\title{
PERANCANGAN KOMIK ILUSTRASI CERITA I MAKDI DAENG RI MAKKA
}

\author{
Risnawati, Alimuddin, Nurabdiansyah \\ Desain Komunikasi Visual Fakultas Seni dan Desain Universitas Negeri Makassar \\ risnhaycnha@gmail.com \\ nurabdiansyah@unm.ac.id \\ alimuddin185@gmail.com
}

\begin{abstract}
Abstrak
Perancangan Komik Ilustrasi Cerita I Makdi Daeng Ri Makka ini dilatarbelakangi oleh dinamika dan perkembangan yang disebabkan oleh arus budaya modern. Cerita rakyat tentang $I$ Makdi Daeng Ri Makka ini tidak banyak diketahui oleh masyarakat Jeneponto sendiri terutama pada kalangan remaja, sedangkan Budaya dan sejarah merupakan salah satu kekayaan bangsa yang harus dipelihara dan dilestarikan. Perancangan ini bertujuan untuk memperkenalkan cerita rakyat daerah Jeneponto tersebut dengan visualisasi dan pengemasan ilustrasi yang relevan dengan era digital saat ini, agar dapat menarik minat masyarakat terutama kalangan remaja untuk menyimak informasi yang diberikan tentang cerita rakyat I Makdi Daeng Ri Makka. Perancangan ini menggunakan metode pengumpulan data berupa observasi, wawancara, studi pustaka, dan dokumentasi. Media yang digunakan dalam perancangan ilustrasi ini adalah media komik. dari perancangan tersebut dihasilkan sebuah media komik ilustrasi cerita I Makdi Daeng Ri Makka
\end{abstract}

Kata kunci: ilustrasi; perancangan; komik; cerita rakya;, I Makdi Daeng Ri Makka

\section{Abstract}

Comic Illustration Design Stories I Makdi Daeng Ri Makka was motivated by the dynamics and developments caused by modern cultural currents. Folklore I Makdi Daeng Ri $M a k k a$ is not widely known by the public Jeneponto itself mainly in teenagers, while culture and history is one of the nation's wealth that must be maintained and preserved. This design aims to introduce the Jeneponto regional folklore with visualization and packaging illustrations that are relevant to today's digital era, in order to attract people, especially among teenagers to listen to the information provided about the folklore I Makdi Daeng Ri Makka. This design uses a data collection methods such as observation, interviews, literature review, and documentation. Media used in the design of this illustration is the medium of comics. from the design produced a comic illustration media stories I Makdi Daeng Ri Makka

Keywords: illustration; design; comics; folklore; I Makdi Daeng Ri Makka

\section{PENDAHULUAN}

Ragam kebudayaan yang tersebar luas di seluruh nusantara dari Sabang sampai Merauke, di antara ragam budaya yang dimiliki berupa pakaian daerah, tari-tarian daerah, makanan khas daerah, lagu daerah, cerita rakyat dari tiap daerah dan masih banyak lagi. Cerita rakyat merupakan cerita dimiliki oleh hampir setiap daerah, disampaikan oleh nenek moyang secara turun temurun. Cerita rakyat dari tiap daerah ini memiliki nilai moral yang baik untuk mendidik anak-anak.

Setiap daerah di Indonesia pada umumnya mempunyai cerita rakyat yang berbeda-beda. Salah satunya yaitu cerita rakyat I Makdi Daeng Ri Makka adalah sebuah cerita rakyat dalam sejarah Turatea yang berasal dari Kabupaten Jeneponto yang menceritakan tentang sebuah peristiwa konflik antar keluarga dari dua kerajaan berbeda yaitu Karaengta Bontotangnga dengan I Makdi Daeng Ri Makka, dalam konflik tersebut menghasilkan pertempuran besar yang mengakibatkan jatuhnya banyak korban dari kedua belah pihak termasuk I Makdi Daeng Ri Makka yang rela berkorban mempertahankan harga dirinya (Faisal, 2012)

Cerita rakyat lokal penting untuk disampaikan agar menarik. Salah satu caranya 
adalah dengan menyajikan sebuah peristiwa yang disuguhkan dengan ilustrasi menarik. Peran ilustrasi bisa mempermudah masyarakat untuk mengerti serta dapat lebih mudah membayangkan peristiwa yang ingin disampaikan. Ilustrasi juga dinilai memiliki peran penting dalam membuat sebuah cerita rakyat lokal menjadi lebih menarik dan mudah dipahami sesuai dengan target masyarakat seperti pelajar agar dapat lebih memahami sebuah peristiwa yang pernah terjadi

Berdasarkan permasalahan tersebut, perancang terdorong untuk memperkenalkan cerita rakyat daerah Jeneponto tersebut dengan visualisasi dan pengemasan ilustrasi yang relevan dengan era digital saat ini, agar dapat menarik minat masyarakat terutama kalangan remaja untuk menyimak pembelajaran tentang emosi yang ada pada cerita rakyat I Makdi Daeng Ri Makka.

Perancangan menurut (Ladjamudin, 2005) menjelaskan bahwa: "perancangan adalah kemampuan untuk membuat beberapa alternatif pemecahan masalah". (Azhar, 2004) menjelaskan "perancangan adalah spesifikasi umum dan terinci dari pemecahan masalah berbasis komputer yang telah dipilih selama tahap analisis.

Terdapat beberapa fungsi ilustrasi secara umum. Adapun fungsi-fungsi dari ilustrasi adalah sebagai berikut (Arifin \& Kusrianto, 2009) Fungsi Deskriptif. Fungsi deskriptif dari ilustrasi adalah menggantikan uraian mengenai sesuatu secara verbal dan naratif dengan menggunakan kalimat panjang. Ilustrasi dapat dimanfaatkan untuk melukiskan sehingga dapat lebih cepat dan lebih mudah dipahami. 2) Fungsi Ekspresif. Fungsi ilustrasi dalam memperlihatkan dan menyatakan sesuatu gagasan, perasaaan, maksud, situasi ataupun konsep yang abstrak menjadi yang nyata sehingga mudah dipahami. 3) Fungsi Analitis atau Struktura. Ilustrasi dapat menunjukkan rincian bagian demi bagian dari suatu bnda ataupun ssitem atau proses secara detail, agar lebih mudah dipahami. 4) Fungsi Kualitatif. Fungsi ini sering digunakan untuk membuat daftar, tabel, grafik, kartun, foto, gambar, sketsa, dan simbol.

Menurut (Rohidi, 1984) yang berpendapat bahwa pengertian gambar ilustrsi berkaitan dengan seni rupa adalah pengambaran sesuatu melalui elemen rupa untuk lebih menerangkan, menjelaskan atau pula memerindah sebuah teks, agar pembacanya dapat ikut merasakan secara langsung melalui sifat-sifat gerak, dan kesan dari cerita yang disajikan. Ilustrasi merupakan bentuk visual dari teks ataupun kalimat. Ilustrasi memperjelas teks ataupun kalimat dengan menggambarkan adegan dalam suatu cerita, maka gambar tersebut secara umum menerangkan karakter atau keseluruhan isi cerita. Tidak hanya itu, ilustrasi juga berfungsi dalam menarik pembaca agar tertarik untuk membaca.

Kehadiran ilustrasi dalam cerita menyebabkan teks akan terbaca secara berkala lalu perhatian akah terarahkan ke ilustrasi (membaca non-verbal) pada saat yang sama mencoba menemukan hubungan antara teks dan ilustrasi, selama proses ini kedua belahan otak terlibat menyimpan memori yang lebih dalam terhadap informasi yang baru masuk. Memberikan gambaran visual yang ada dalam isi sebuah tulisan terkait cerita yang disampaikan dan mewakilinya dalam bentuk bergambar. Juga sebagai sarana dalam mengungkapkan pengalaman terhadap suatu kejadian yang diekspresikan dalam sebuah gambar. Karakteristik mendasar mengenai ilustrasi adalah memberikan informasi yang disajikan dalam bentuk tertulis lalu mewakilinya dengan gambaran visual yang representatif (Terzaghi, Benny Krisna, Peck, \& Witjaksono, 1987).

(Danandjaja, 1997) mengemukakan bahwa cerita rakyat merupakan salah satu bentuk folklor. Folklor itu sendiri adalah sebagian kebudayaan suatu kolektif yang tersebar dan diwariskan turun-temurun diantara macam kolektif apa saja secara tradisional dalam versi yang berbeda, baik dalam bentuk lisan maupun contoh yang disertai gerak isyarat atau alat pembantu pengingat.

Menurut (Asfandiyar \& Iskandar, 2007) dongeng adalah cerita rekaan, cerita rakyat yang tidak benar-benar terjadi dan bermanfaat bagi perkembangan anak. Bila perkembangan secara kognitif (pengetahuan), afektif (perasaan), sosial, dan aspek konatif (penghayatan).

Fungsi cerita rakyat adalah sebagai sarana pendidikan, harga diri, dan sebagai hiburan atau pelipur lara. Berkaitan dengan hal 
di atas, (Atmazaki, 1990) menyatakan bahwa fungsi cerita rakyat yaitu untuk mengekspresikan gejolak jiwa dan renungannya tentang kehidupan oleh masyarakat terdahulu, untuk mengukuhkan solidaritas masyarakat, dan digunakan untuk memuji raja, pemimpin, dan orang atau benda yang dianggap suci, keramat, atau berwibawa oleh kolektifnya.

Penciptaan Buku Ilustrasi Danau Kastoba Bawean Sebagai Upaya Memperkenalkan Produk Budaya Lokal Bagi Anak-Anak, Oleh (Ifadhah, 2015). Penulis pada jurnal tersebut melakukan perancangan menggunakan metode kualitatif. Analisis data pada penelitian ini bersifat induktif/kualitatif berdasarkan Fakta-fakta yang ditemukan di lapangan dan kemudian dikonstruksikan menjadi hipotesis atau teori. Hasil penelitian kualitatif lebih menekankan makna daripada generalisasi. Dengan pendekatan kualitatif, diharapkan data yang didapatkan dapat sesuai, terperinci, dan menunjang kelanjutan penciptaan buku ilustrasi berbasis pop up cerita rakyat tentang Danau Kastoba Bawean sebagai upaya memperkenalkan produk budaya lokal bagi anak anak. Hasil yang dicapai dari penelitian ini yaitu sebuah buku ilustrasi berbasis pop up yang dikhususkan untuk anakanak.

\section{METODE PENELITIAN}

Jenis penelitian ini adalah penelitian perancangan dengan metode analisa data. Analisis data/informasi, dalam Desain Komunikasi Visual berdasarkan perspektif ilmu komunikasi terdapat sekurang-kurangnya beberapa komponen komunikasi yang harus dianalisis, yaitu antara lain analisa data mengenai: materi komunikasi (materi pesan), target audiens/konsumen (khalayak sasaran), saluran/media komunikasi, komponenkomponen visual yang akan membentuk materi pesan menjadi berwujud visual, dan lain-lain.

Dalam proses pengumpulan data yang dilakukan penulis, teknik pengumpulan data yang digunakan yaitu teknik pengumpulan data secara primer dan sekunder. Di mana penulis melakukan penelitian dan observasi ke lokasi lapangan secara langsung, kemudian didukung oleh data sekunder dari buku, jurnal dan website yang bersangkutan dengan materi yang akan diangkat.

Observasi lapangan dilakukan adalah dengan pengamatan secara langsung ke lokasi pemakaman rakyat i Makdi Daeng ri Makka, Buku dan situs cerita rakyat Jeneponto, serta buku berbahasa aksara lontara dari cerita rakyat Jeneponto yang telah diteliti dan diterjemahkan. Wawancara dilakukan setelah melakukan observasi dan melihat fenomena yang terjadi terkait dengan permasalahan yang diangkat. Dalam hal ini penulis mewawancarai untuk memperoleh data dengan memberikan pertanyaan yang terkait kepada narasumber, yaitu Muh. Faisal, S.Pd., M. Pd yang merupakan dosen pengajar Fakultas Keguruan Dan Ilmu Pendidikan Universitas Muhammadiyah Makassar mengenai Cerita rakyat Jeneponto, I Makdi Daeng Ri Makka.

Adapun target audience yang akan dianlisis tiga jenis yaitu demografis yang menentukan yaitu usia dan pendidikan, lalu secara psikografis yang menentukan kepribadian dan secara geografis perancangan ini ditunjukkan kepada target audience yaitu masyarakat Sulawesi Selatan.

Analisa Objek Materi Komunikasi memuat latar belakang terjadinya konflik di Butta Turatea, ada sebuah cerita yang beredar dan mewarisi secara turun temurun dari satu generasi ke generasi selanjutnya. Cerita tersebut berkisah tentang keberanian seorang I Makdi Daeng Ri Makka, seorang pemberani kerajaan Gowa di Binamu dan pernah ditawan oleh kompeni. Dia dimuliakan di Layu, pemimpin di Balandangan, penguasa di Binamu, dan di persiapkan untuk menjadi Raja di Turatea.

Analisa Target Audiens membuat media ilustrasi yang dapat memberikan informasi mengenai kisah I Makdi Daeng Ri Makka sebagai sejarah yang pernah terjadi di Jeneponto, merupakan tujuan khusus dari perancangan ini, mengidentifikasi target audience merupakan hal yang penting, karena setelah menentukan informasi apa yang akan disampaikan, pertanyaan selanjutnya kepada siapa informasi tersebut disampaikan.

Segmentasi Geografis; 1) Indonesia dan Mancanegara, 2) Kab. Jeneponto, Sulawesi Selatan dan 3) Masyarakat kalangan remaja hingga dewasa. Segmentasi Demografis Seperti yang telah dipaparkan sebelumnya, 
materi informasi yang disajikan yaitu mengenai sejarah kisah I Makdi Daeng Ri Makka yang dimana materi ini diperuntukan pada targert audience: 1) Usia \& Jenis Kelamin: Laki-Laki (17 $\quad-30$ Tahun): Perempuan (17 - 30 Tahun). 2) Pekerjaan/ Profesi: Peserta didik, dan semua profesi 3) Kelas Sosial: Semua Kalangan. Segmentasi Psikografis, materi informasi mengenai sejarah kisah I Makdi Daeng Ri Makka merupakan produk yang tidak semua audience menyukai hal tersebut, maka target audiens akan difokuskan kepada audiens yang memiliki rasa ingin tahu yang tinggi terutama informasi mengenai sejarah lokal, menyukai tentang cerita sejarawan dan tertarik pada history tersebut, serta update terhadap teknologi yang tren saat ini.

Analisa Branding, terdiri dari analisa kompetitor yang pada dasarnya media informasi adalah sarana yang digunakan untuk memberikan informasi peristiwa-peristiwa yang terjadi kepada masyarakat umum secara cepat. Melalui media tersebut informasi tersampaikan lebih efektif, terlebih perkembangan media informasi saat ini sudah berkembang dengan adanya media ilustrasi yang sangat membantu menyampaikan informasi. Dalam perancangan ini, Setelah melakukan riset dari berbagai macam materi dapat disimpulkan bahwa dalam cerita I Makdi Daeng Ri Makka, yang tertuang dalam naskah lontarak makassar terdapat sebuah sistem nilai yang menjadi patronasi kebudayaan Makassar. Tokoh I Makdi Daeng Ri Makka rela berkorban demi martabat dan harga diri.

Analisis Strategi Komunikasi dalam hal ini analisis tujuan komunikasi dalam penelitian ini, memiliki masalah yaitu kurang dikenalnya tokoh I Makdi Daeng Ri Makka serta data-data mengenai tokoh ersebut masih sangat minim, oleh karena itu tujuan komunikasi dalam penelitian yaitu untuk mengkomunikasikan informasi mengenai I Makdi Daeng Ri Makka secara lebih efektif dan dengan mengikuti gaya anak milenial melalui media bergambar ilustrasi. Melalui rancangan tersebut data-data sangat mudah di pahami dan ditangkap oleh target audience.

Brainstorming atau curah pendapat dilakukan untuk mengumpulkan ide-ide yang mungkin menjadi solusi dari perancangan. Berikut ini adalah alur dari proses perancangan ilustrasi I Makdi Daeng Ri Makka melalui proses

Brainstorming dan Mindmaping digunakan untuk mempetakan hasil pemikiran dari analisis yang dilakukan dan memiliki keterkaitan sebelum melanjutkan pada pencurahan ide pada proses Brainstroming.

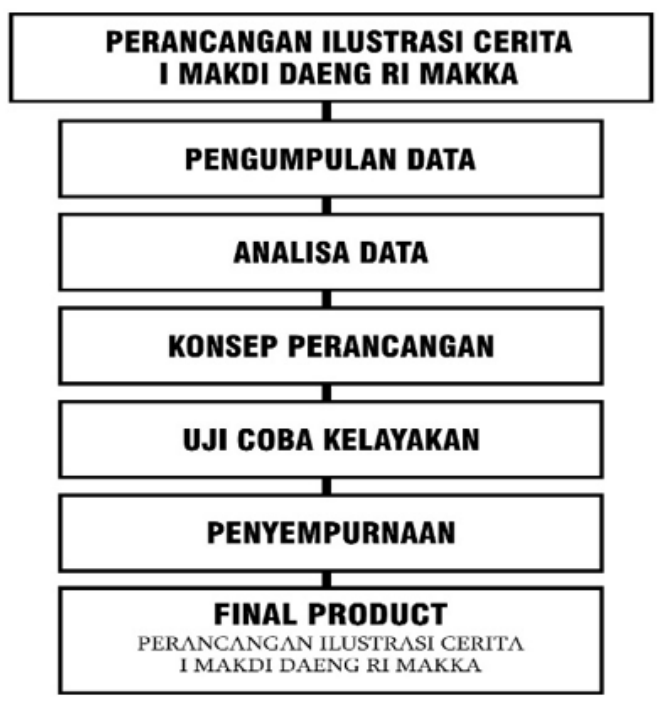

Gambar 1. Skema Perancangan

\section{HASIL DAN PEMBAHASAN}

Media utama dalam perancangan ini adalah Komik ilustrasi I Makdi Daeng Ri Makka. Ada beberapa bahan pertimbangan dalam Komik ilustrasi sebagai media utama.

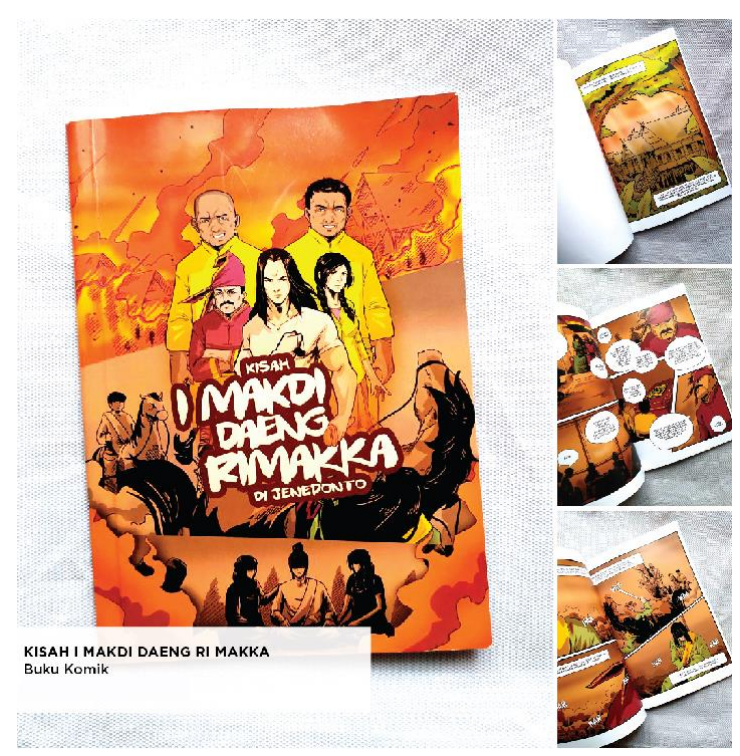

Gambar 2. Komik I Makdi Daeng Ri Makka 
(Ulfa, Putri, Budiardjo, \& Prayitno, 2016) menyatakan komik Ilustrasi termasuk buku yang diminati oleh banyak masyarakat milenial saat ini, hal tersebut dapat dilihat dari observasi di berbagai gramedia di makassar yang sangat laku merupakan buku ilustrasi anak, remaja dll.

Mengingat saat ini merupakan era yang dimana sangat berkembang, bukan hanya teknologi yang berkembang tetapi beberapa buku juga sudah berkembang dengan gaya yang berbeda-beda, akan efektif bila informasi yang akan disampaikan juga berbentuk ilustrasi, media yang akan digunakan dalam menginformasikan cerita tentang cerita I Makdi Daeng Ri Makka yang dimana media yang digunakan sebelumnya yaitu hanya bukubuku cerita sejarawan yang pada umumnya dan terdapat beberapa kekurangan mulai dari bahan, tulisan dan gambar yang kurang jelas.

Dalam semangat baca masyarakat tentang cerita I Makdi Daeng Ri Makka di Indonesia saat ini sangat kurang seperti temuan UNDP (United Nations Development Programs) pada tahun 2011 bahwa Indonesia merupakan peringkat 112 dari 175 Negara (Id.undp.org, 2017), dengan kata lain tampilan visual lebih dinikmati. Tipografi yang akan digunakan adalah font Deadstock Demo sebagai font utama, Font Nurky buzz Demo dipilih karena terinspirasi dari tulisan yang terdapat yang cukup terlihat manual.

Media utama dalam perancangan ini adalan Komik dengan Teknik ilustrasi digital menggunakan Software Adobe Illustrator dengan jumlah halaman sebanyak 31 halaman. Illustrasi dibawah ini menyajikan informasi mengenai kisah sejarah perjuangan I Makdi Daeng Ri Makka. Ilustrasi tersebut memiliki beberapa materi inti sehingga terdapat tiga bagian yaitu materi awal, materi inti, dan materi akhir. materi awal memberikan informasi mengenai pembahasan awal sebagai pengantar pembahasan untuk materi inti.

Komposisi warna yang akan digunakan dalam perancangan ini. Berdasarkan konsep desain yang akan diangkat, dalam hal ini warna yang diterapkan adalah warna coklat yang melambangkan tanah, sebab di daerah jeneponto daerah gurung, merah melambangkan api sebab di daerah jeneponto memegang siri na pacce artinya harga diri yang keras (emosional) dan kokoh pendiriannya, warna kuning melambangkan kebangsawanan dan kerajaan, warna hijau melambangkan warna alam (kesuburan), warna putih melambangkan air (kesucian), warna hitam melambangkan warna keanggunan, percaya diri, dramatis dan ketegasan dan bisa juga diartikan sebagai warna melambangkan kesedihan.

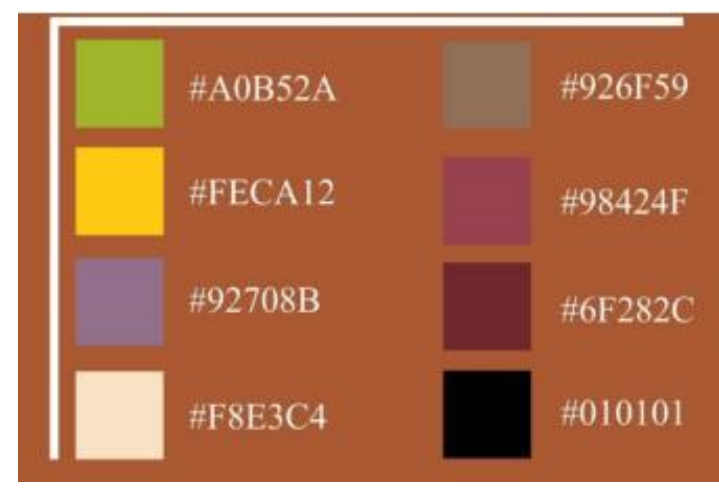

Gambar 3. Skema Warna

Konsep Panel, Panel adalah urutan dari setiap gambar atau materi yang digunakan untuk menjaga kelanjutan dari cerita yang sedang berlangsung. Berikut ini adalah konsep panel yang akan digunakan untuk komik ilustrasi yang akan dirancang.

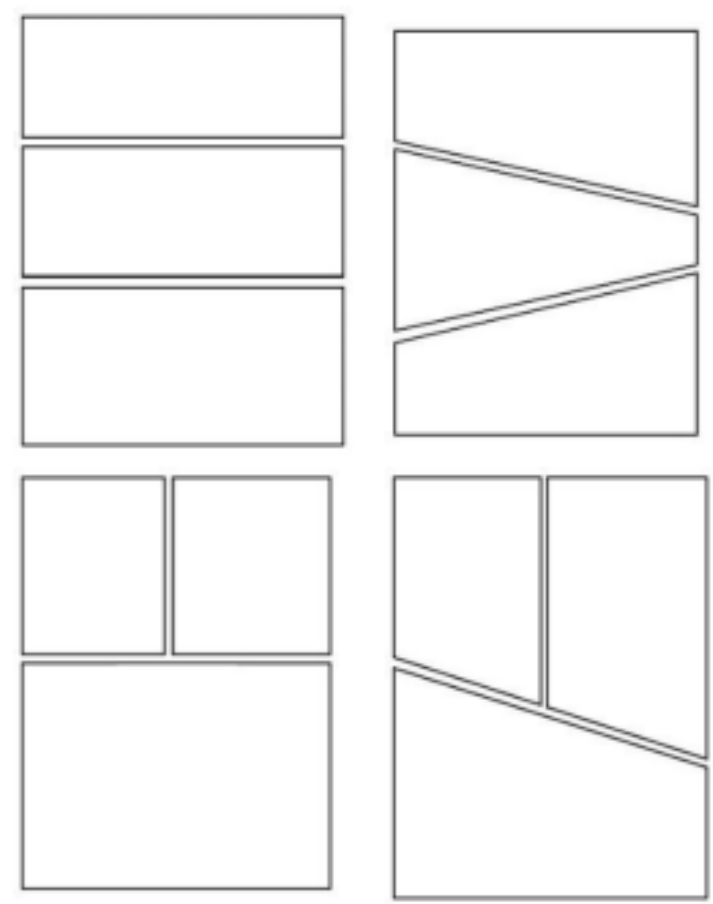

Gambar 4. Penggunaan Panel Komik 
Tipografi yang akan digunakan adalah font Deadstock Demo sebagai font utama, Font Nurky buzz Demo dipilih karena terinspirasi dari tulisan yang terdapat yang cukup terlihat manual.

\section{MURKY BUZZ DEMO}

ABCDEFGHIJKLMN

\section{OPQRSTUVWXYZ}

\section{ABCDEFGHIJKLM NOPQRSTUVWXYZ}

\section{$1234567890 . . ! ?$}

\section{Gambar 5. Tipografi dalam Komik}

Adapun proses desain dari perancangan Komik ilustrasi ini ialah sketsa karakter, sketsa adegan, dan digitalisasi tahap Layout dan finishing. Proses pertama ialah sketsa karakter dimana karakter yang akan dimasukkan di dalam media perancangan bergaya visual semirealism cartoon terlebih dahulu pada sketsa berdasarkan sumber data yang didapatkan. Berikut ini merupakan gamba sketsa karakter I Makdi Daeng Ri Makka yang digambar berdasarkan sumber data yang telah didapatkan dari hasil penelitian.

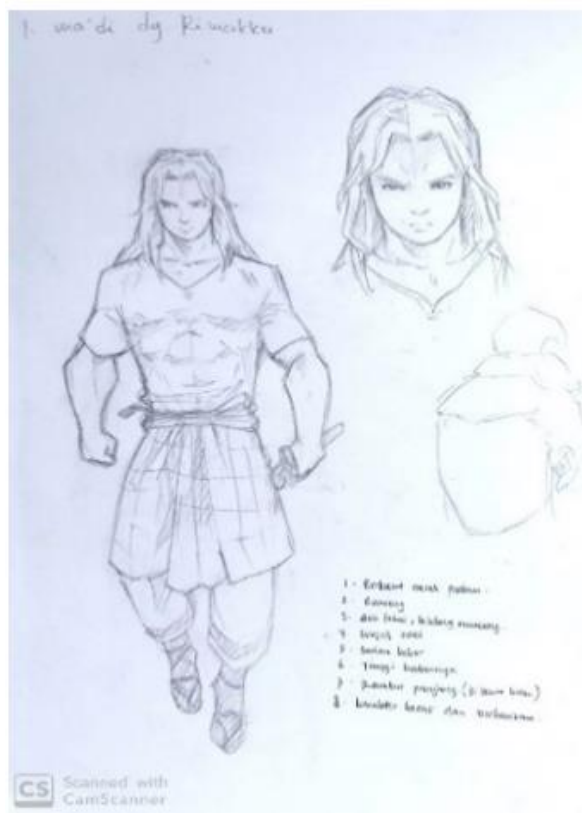

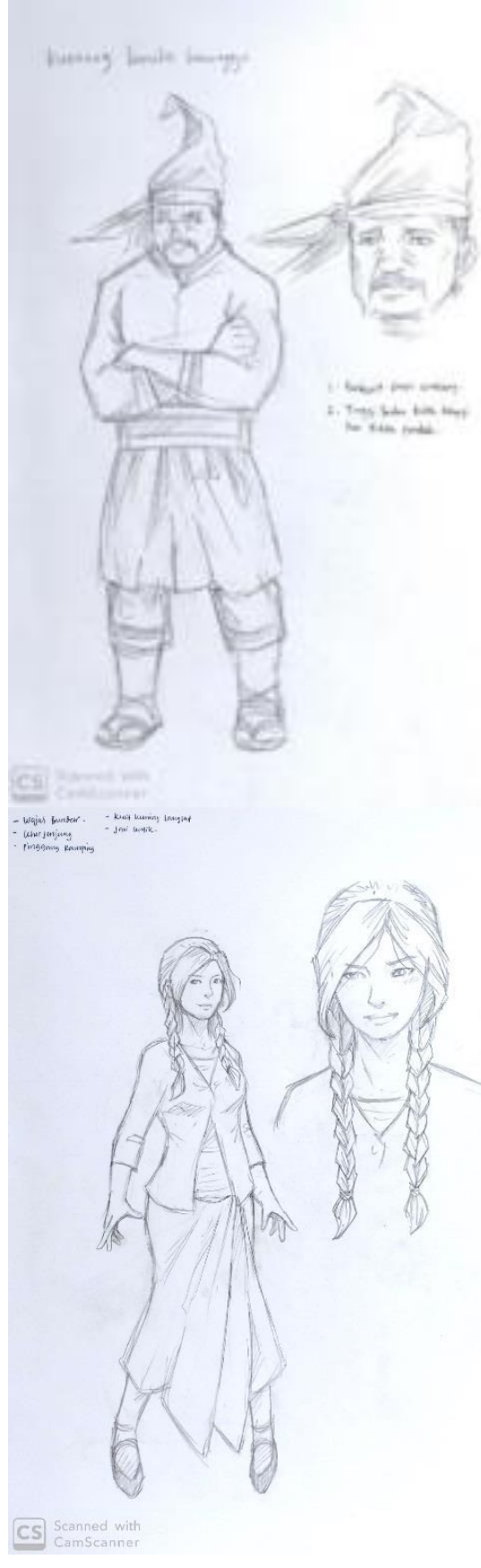

Gambar 5. Sketsa Karakter Tokoh Komik

Berikutnya adalah sketsa adegan di mana adegan akan digambar kembali menjadi sebuah sketsa kasar yang disesuaikan dengan sumber data yang di dapatkan. Salah satu sketsa adegan pada gambar di bawah ini merupakan adegan dimulainya pertempuran antara I Makdi Daeng Ri Makka dengan Karaengta Bontotangnga yang akan diakhiri dengan I Makdi Daeng Ri Makka. 


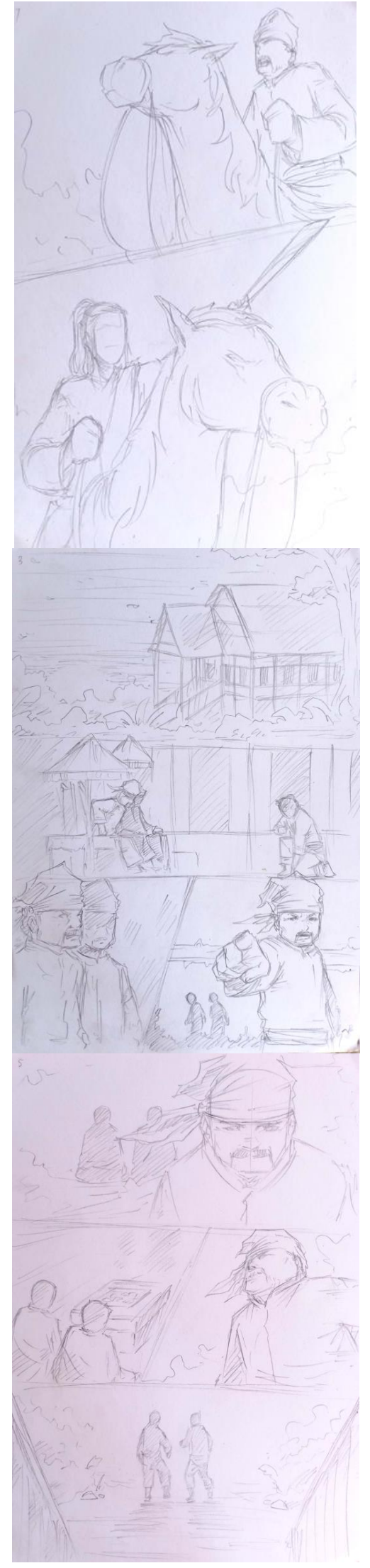

Gambar 6. Beberapa Sketsa Adegan
Setelah menentukan sketsa karakter dan adegan terpilih, dilanjutkan dengan program Adobe Ilustrator dimana pada proses tersebut merupakan proses digitalisasi dan finishing.
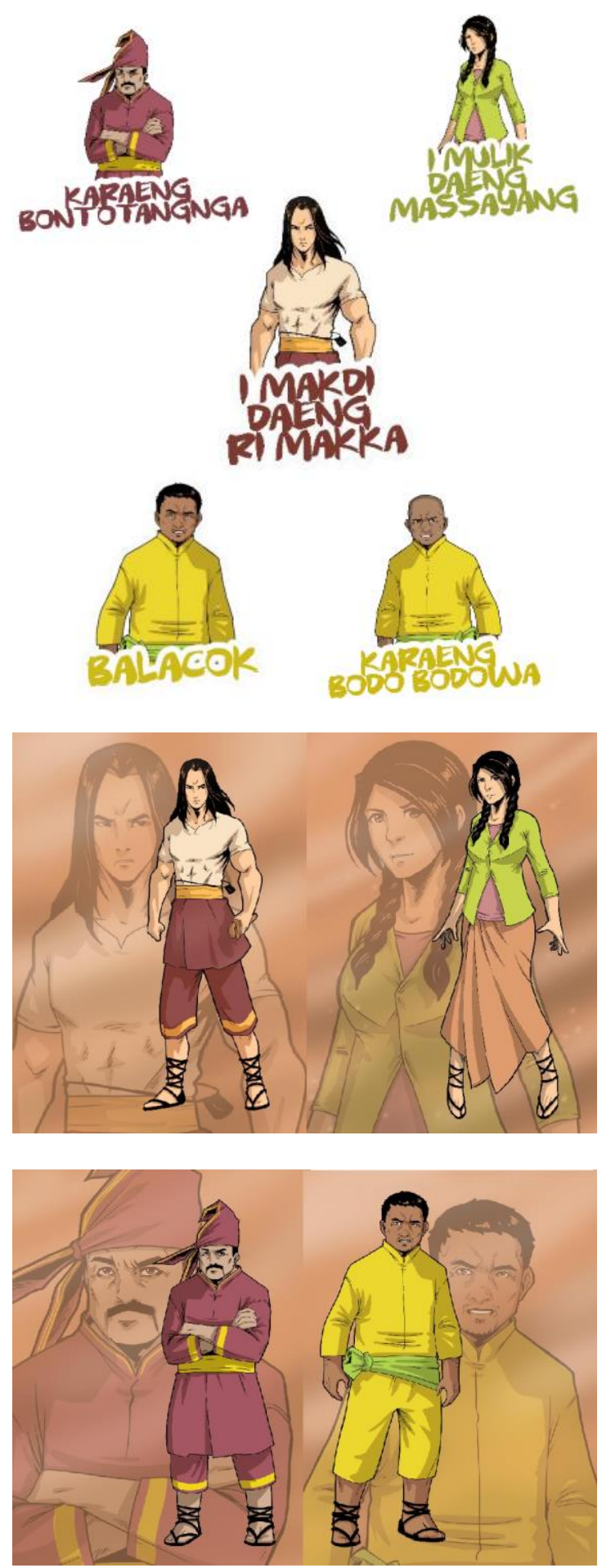

Gambar 7 Digital Coloring Karakter Tokoh Komik 

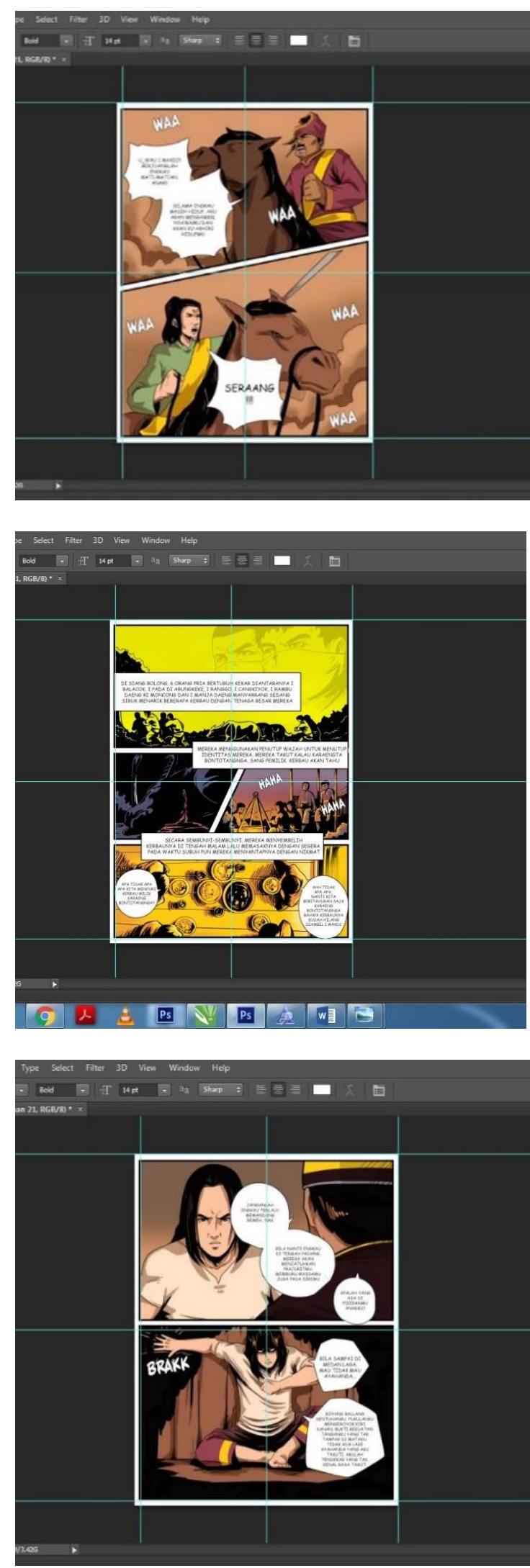

Gambar 7 Digital Coloring Adegan Komik
Illustrasi dalam komik ini menyajikan informasi mengenai kisah sejarah perjuangan I Makdi Daeng Ri Makka. Ilustrasi tersebut memiliki beberapa materi inti sehingga terdapat tiga bagian yaitu materi awal, materi inti, dan materi akhir. materi awal memberikan informasi mengenai pembahasan awal sebagai pengantar pembahasan untuk materi inti.

\section{SIMPULAN DAN SARAN Simpulan}

Dari hasil perancangan komik ilustrasi cerita I Makdi Daeng Ri Makka, maka dapat disimpulkan yaitu Media ini dirancang berdasarkan permasalahan yang muncul, yang di mana usia remaja hingga dewasa kurangnya minat membaca yang monoton dengan tulisan, maka di sini penulis memperbarui kisah I Makdi Daeng Ri Makka dengan memvisualisasikan melalui media komik.

Dengan memiliki target audience pada usia remaja-dewasa maka mulai dengan gaya, layout, warna, dan font harus mengikuti gaya audience selaku target pada perancangan ini. Dengan memberikan Informasi mengenai I Makdi Daeng Ri Makka dalam bentuk media informasi dapat menjadi sumber informasi bagi generasi selanjutnya yang khususnya Kab. Jeneponto Sulawesi Selatan.

\section{Keterbatasan}

Dalam melaksanakan penelitian ini, keterbatasan yang ditemui penulis ialah kurangnya data-data mengenai kisah I Makdi Daeng Ri Makka dan dokumentasi I Makdi Daeng Ri Makka juga tidak ada sama sekali, karena sejarah I Makdi Daeng Ri Makka tidak begitu banyak publish sehingga penulis mengalami kendala. Dengan adanya kumpulan data akan memberi nilai tambah pada informasi yang akan disajikan melalui studi kepustakaan dan wawancara penulis mendapatkan beberapa data yang akan di angkat. Adapun keterbatasan dengan melakukan Teknik manual penulis harus lebih teliti menerjakannya.

\section{Saran}

Perancangan Komik Ilustrasi yang dilakukan oleh penulis tentunya sangat jauh dari kata sempurna, dan tentunya banyak 
kekurangan disana sini karena keterbatasan penulis. Oleh karena itu perlu dikembangkan lebih lanjut, agar informasi-informasi dan data yang diangkat bisa lebih rinci. Maka adapun beberapa saran yaitu sebagai berikut;

1. Media yang dipilih untuk digunakan sebagai media informasi sebaiknya merupakan media yang up to date (terbaru), agar lebih menyasar masyarakat moderen dan masyarakat usia remaja dewasa, karena informasi tentang sejarah justru hilang dimayoritas kalangantersebut.

2. Penyajian Informasi sebaiknya memperhatikan aspek-aspek target audience, sehingga dapat menarik minat dan informasi tersebut dapat tersampaikan dengan baik.

\section{REFERENSI}

Arifin, S., \& Kusrianto, A. (2009). Sukses Menulis Buku Ajar dan Referensi. Jakarta: Grasindo.

Asfandiyar, A. Y., \& Iskandar, S. (2007). Cara pintar mendongeng. Dar Mizan.

Atmazaki. (1990). Ilmu sastra: teori dan terapan. Angkasa Raya.

Azhar, S. (2004). Sistem Informasi Manajemen-Konsep dan Pengembangannya. Edisi Ketiga,(Bandung: Lingga Jaya, 2004).

Danandjaja, J. (1997). Folkor Indonesia: Ilmu Gosip, Dongeng, dan lain-lain (Cetakan Kelima). Jakarta: PT Pustaka Utama Grafiti.

Faisal, M. (2012). Sejarah perjalanan I Makdi Daeng Ri Makka.

Id.undp.org. (2017). Indeks Pembangunan Manusia Indonesia Meningkat tapi Kesenjangan Masih Tetap Ada. Retrieved from Id.undp.org website: https://www.id.undp.org/content/indones $\mathrm{ia} / \mathrm{id} / \mathrm{home} 1 /$ presscenter/pressreleases/20 17/03/22/indonesia-s-humandevelopment-index-rises-but-inequalityremains-.html

Ifadhah, H. T. (2015). TA: Penciptaan Buku Ilustrasi Berbasis Pop Up Tentang Cerita Rakyat Danau Kastoba Bawean sebagai Upaya Memperkenalkan Produk Budaya Lokal Bagi Anak-anak. Institut Bisnis dan Informatika Stikom Surabaya.
Ladjamudin, A.-B. Bin. (2005). Analisis dan desain sistem informasi. Yogyakarta: Graha Ilmu, 1, 1-6.

Rohidi, T. R. (1984). Lintasan peristiwa \& tokoh seni rupa Indonesia baru. IKIP Semarang Press.

Terzaghi, K., Benny Krisna, R., Peck, R. B., \& Witjaksono, B. (1987). Mekanika Tanah Dalam Praktek Rekayasa. Penerbit Erlangga, Jakarta.

Ulfa, S., Putri, V., Budiardjo, H., \& Prayitno, S. (2016). Perancangan Buku Komik Ludruk Berbasis Ilustrasi Digital Guna Mengenalkan Kembali Kesenian Tradisional kepada Remaja. 5(2). 